\title{
Thermodynamic investigations of the copigmentation process between strawberry anthocyanins and rose petal polyphenols (Rosa damascena Mill.) at different temperatures
}

\author{
Ivalina Petrova ${ }^{1,1}$, Kiril Mihalev ${ }^{2}$, Vasil Shikov ${ }^{2}$, and Vanya Gandova ${ }^{3}$ \\ ${ }^{1}$ Sofia Technical University, branch Plovdiv, Mathematics, Physics and Chemistry Department, \\ 4002Plovdiv, Bulgaria \\ ${ }^{2}$ University of Food Technologies, Department of Food Preservation and Refrigeration Technology, \\ 4002 Plovdiv,Bulgaria \\ ${ }^{3}$ University of Food Technologies, Analytical andPhysicochemical Department, 4002 Plovdiv, \\ Bulgaria
}

\begin{abstract}
In this study the model systems between strawberry anthocyanins as pigment and rose polyphenols as copigment was investigated. The solutions were prepared from 1:2 to 1:10 pigment:copigment. The addition of increasing concentrations of rose petal polyphenols resulted in a gradual increase of hyperchromic effect. The absorption was determined at heating system from 20 to $50^{\circ} \mathrm{C}$ and following cooling the same system from 50 to $20^{\circ} \mathrm{C}$. All calculated thermodynamic parameters were negative. The copigmentation reaction was determined as spontaneous, exothermic and thermally reversible.
\end{abstract}

\section{Introduction}

The attractive bright red color is the major visual quality attribute strongly affecting consumer acceptance both of fresh and processed strawberry fruits. Anthocyanins are not only important determining the aesthetic value of foods and beverages, but also play a significant role from a nutritional being bioavailable dietary antioxidants [1-3]. Copigmentation is a color-stabilizing mechanism in which an anthocyanin and another, usually colorless, molecule (copigment) form complexes predominately by $\pi-\pi$ stacking interaction in the aqueous environment of the plant vacuoles [4]. Mostly with polyphenols the biological principle is allowed for color within epidermal flower tissues [5].

Distilled (de-aromatized) rose (Rosa damascena Mill.) petals, a by-product from the essential oil industry, were established as a parent of polyphenols [6]. The pigmentstabilizing ability was seen in a real food matrix [7-9].

1 Corresponding author: ivalinapetrova.com@abv.bg 
The present study evaluated the effects of principal factors such as copigment concentration and temperature into efficiency of rose petal polyphenols, which would allow optimization of their application as natural anthocyanin-stabilizing agents in strawberry processing.

\section{Experimental}

\subsection{Chemicals}

Frozen strawberries (Fragaria $\times$ ananassaDuch., cv. Siabelle, harvest 2014) were provided by Cima 99 Ltd. (Striama, Bulgaria). Lyophilized crude extract of rose was used as polyphenols [7]. For the McIlvaine buffer with $\mathrm{pH}=3.4$ was used citric acid monohydrate and disodium hydrogen phosphate dodecahydrate. The reagents were provided from Merck (Darmstadt, Germany). For adsorption process the resin Amberlite XAD 16N from Sigma Aldrich Co. (St. Louis, MO, USA) was used.

\subsection{Different processes for determination of anthocyanins}

Extraction process for investigated strawberry anthocyanins and their purification was described by [7]. Frozen strawberries (Fragaria $\times$ ananassa Duch.) were handed and homogenized in a beaker. The obtained mix was processed by extraction with ethanol and temperature $4{ }^{\circ} \mathrm{C}$. As solvent was used hydrochloric acid. All obtained fractions were filtered. After that evaporation of organic solvent was provide at $30{ }^{\circ} \mathrm{C}$ and vacuum. Different additions as sugars, salts and amino acids after purification were removed in a column with size $465 \times 30 \mathrm{~mm}$ and filled with adsorption resin Amberlite XAD 16N. After purification the resin was conditioned and equilibrated. Quantities of $500 \mathrm{ml}$ methanol and $1000 \mathrm{ml}$ water were used. It's done acidification with Trifluoroacetic acid and $\mathrm{pH}=2$. Quarter liter of aqueous solution prepared of strawberry extract was placed in the column rinsed with $1000 \mathrm{ml}$ of acidified water. After that the organic solvent was evaporated under vacuum and at temperature $30^{\circ} \mathrm{C}$. To separate anthocyanins from colorless compounds after purification was performed by extracting the aqueous phase at three times using the same volume of ethyl acetate. After evaporation and concentration with vacuum and at temperature $30^{\circ} \mathrm{C}$, lyophilization was providing for $72 \mathrm{~h}$. The total monomeric anthocyanins were determined by the $\mathrm{pH}$-differential method. The results were presented as equivalents of pelargonidin 3glucoside.

\subsection{Solutions preparation and spectrophotometric measurements}

Solutions between strawberry extract and rose polyphenols were prepared in $0.1 \mathrm{M}$ McIlvaine buffer with $\mathrm{pH}=3.4$ and using to determine a total anthocyanins. Spectrophotometric determinations. Absorption spectra in the visible part of the spectrum were recorded with a spectrophotometer type UV. The apparatus is supplied with software from for graphical presentation. The path length is a constant $1 \mathrm{~cm}$ and measured by appropriate cuvettes.

All samples were thermostated before measurements with VEB MLW PRUFGEPATEWERK Medingens at different temperatures between 20 to $50{ }^{\circ} \mathrm{C}$ at heating and after cooling at 50 to $20^{\circ} \mathrm{C}$.

\subsection{Analysis of statistical determination}


OriginPro 7.0 was used for calculations. Two parallel experiments repeated. Regression analysis was performed. Obtained coefficients of variation were determined less of $2 \%$.

\section{Results and discussion}

Different interactions between strawberry anthocyanins (pigment) and rose petal polyphenols (copigment) were studied spectrophotometrically in model solutions at $\mathrm{pH}$ value $(\mathrm{pH} 3.4)$, which is similar to that of direct strawberry juice. The systems, at molar pigment/copigment ratios from $1: 2$ to $1: 10$, were heated gradually from room temperature $\left(20{ }^{\circ} \mathrm{C}\right)$ to $50{ }^{\circ} \mathrm{C}$ and subsequently cooled to $20^{\circ} \mathrm{C}$.

Since the pigment concentration was constant, the spectral variations observed, as illustrated in Figure 1. In general concentrations of rose petal polyphenols resulted in a gradual magnification of adsorption intensity (hyperchromic effect, $\Delta \mathrm{A}$ ) (Table 1), which clearly indicates an intermolecular copigmentation reaction. The corresponding change of the wavelength of the spectrum (bathochromic effect, $\Delta \lambda \max$ ) was negligible.

Increasing the temperature of the model solutions from 20 to $50{ }^{\circ} \mathrm{C}$ (in steps of $10{ }^{\circ} \mathrm{C}$ ) caused lead to decrease of the hyperchromic effect implying a dissociation complex (Figure 1). Interestingly, cooling the systems from 50 to $20{ }^{\circ} \mathrm{C}$ led to the re-establishment of the copigmentation interaction, shifting the reaction equilibrium toward the complex formation (Figure 2). The latter assumption is supported by the observed absorption spectra maximum intensities (Figure 1). This behavior of the pigment/copigment system studied compared with this reported for the malvin-rutin [11] and malvidin 3-O-glucoside with syringic/vanillic/pcoumaric acid [12] systems and good correlations were observed.

The K (equilibrium constant) of the copigmentation reaction was determined using the equation with dependence between absorbance $\mathrm{A}$ and $\mathrm{A}_{0}$ with and without copigment.

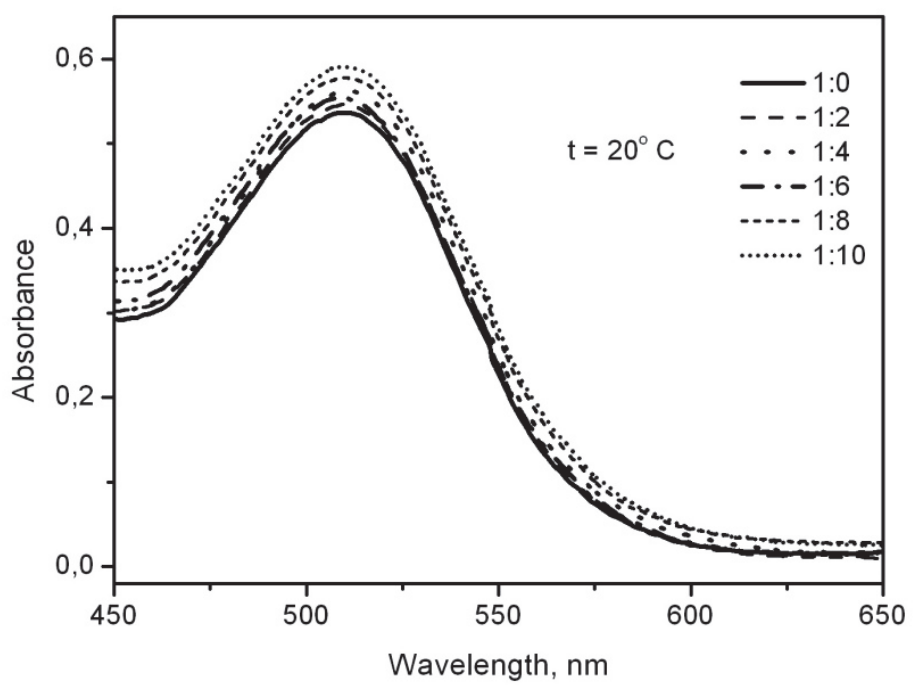

Fig. 1. Absorbance in model solutions of strawberry anthocyanins and rose petal polyphenols: $20^{\circ} \mathrm{C}$, before heating from 20 to $50{ }^{\circ} \mathrm{C}$ (in $10^{\circ} \mathrm{C}$ steps). 
Table 1. Bathochromic ( $\Delta \lambda \max )$ and hyperchromic $(\Delta \mathrm{A})$ effects in couple strawberry anthocyanins:rose petal polyphenols at different pigment:copigment ratio

\begin{tabular}{|c|c|c|c|c|c|}
\hline $\begin{array}{c}\text { Molar } \\
\text { pigment/co } \\
\text { pigment ratio }\end{array}$ & $\Delta \lambda_{\max }, \mathbf{n m}$ & $\Delta \mathbf{A}, \%$ & $\begin{array}{c}\text { Molar } \\
\text { pigment/co } \\
\text { pigment ratio }\end{array}$ & $\Delta \lambda_{\max }, \mathbf{n m}$ & $\Delta \mathrm{A}, \%$ \\
\hline \multicolumn{3}{|c|}{$20{ }^{\circ} \mathrm{C}(\mathrm{H})$} & \multicolumn{3}{|c|}{$20^{\circ} \mathrm{C}(\mathrm{C})$} \\
\hline $1: 2$ & 1 & 3.64 & $1: 2$ & 0 & 0.32 \\
\hline $1: 4$ & 1 & 6.13 & $1: 4$ & 0 & 2.45 \\
\hline $1: 6$ & 2 & 6.70 & $1: 6$ & 0 & 5.72 \\
\hline $1: 8$ & 3 & 11.30 & $1: 8$ & 0 & 7.35 \\
\hline $1: 10$ & 3 & 15.13 & $1: 10$ & 0 & 9.15 \\
\hline \multicolumn{3}{|c|}{$30^{\circ} \mathrm{C}(\mathrm{H})$} & \multicolumn{3}{|c|}{$30^{\circ} \mathrm{C}(\mathrm{C})$} \\
\hline $1: 2$ & 1 & 2.98 & $1: 2$ & 0 & 0.65 \\
\hline $1: 4$ & 2 & 5.76 & $1: 4$ & 1 & 2.13 \\
\hline $1: 6$ & 2 & 5.76 & $1: 6$ & 0 & 5.57 \\
\hline $1: 8$ & 2 & 9.15 & $1: 8$ & 0 & 7.54 \\
\hline $1: 10$ & 2 & 11.93 & $1: 10$ & 0 & 9.18 \\
\hline \multicolumn{3}{|c|}{$40^{\circ} \mathrm{C}(\mathrm{H})$} & \multicolumn{3}{|c|}{$40^{\circ} \mathrm{C}(\mathrm{C})$} \\
\hline $1: 2$ & 0 & 3.14 & $1: 2$ & 0 & 0.68 \\
\hline $1: 4$ & 0 & 3.98 & $1: 4$ & 0 & 4.44 \\
\hline $1: 6$ & 1 & 7.58 & $1: 6$ & 0 & 7.52 \\
\hline $1: 8$ & 0 & 9.02 & $1: 8$ & 0 & 4.44 \\
\hline $1: 10$ & 0 & 12.78 & $1: 10$ & 1 & 10.25 \\
\hline \multicolumn{3}{|c|}{$50^{\circ} \mathrm{C}(\mathrm{H})$} & & & \\
\hline $1: 2$ & 0 & 0.16 & & & \\
\hline $1: 4$ & 0 & 4.72 & & & \\
\hline $1: 6$ & 0 & 7.93 & & & \\
\hline $1: 8$ & 1 & 4.89 & & & \\
\hline $1: 10$ & 0 & 10.28 & & & \\
\hline
\end{tabular}




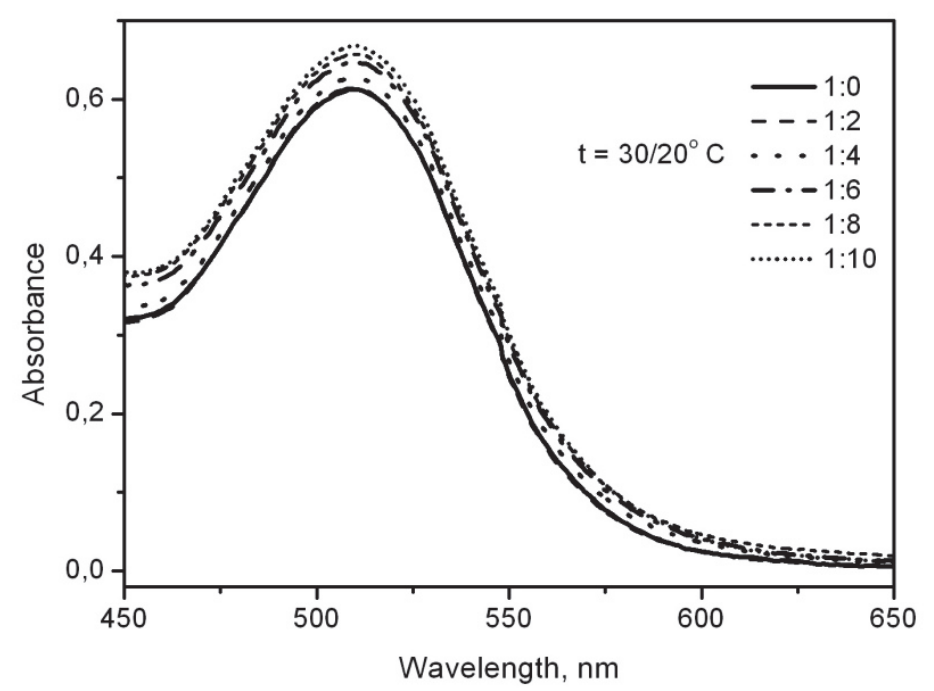

Fig. 2. Absorption spectra of model solutions of strawberry anthocyanins and rose petal polyphenols at different molar pigment/copigment ratios: $20^{\circ} \mathrm{C}$, after cooling from 50 to $20^{\circ} \mathrm{C}$ (in $10^{\circ} \mathrm{C}$ steps).

The determination of the equilibrium constant allowed calculating the different Gibbs free energys [14]:

$$
\Delta G=-\mathrm{RT} \ln K
$$

where $\mathrm{R}$ is the universal gas constant, $\mathrm{T}$ is the absolute temperature $(\mathrm{K})$.

The enthalpy change $(\Delta \mathrm{H})$ was calculated applying the van't Hoff equation:

$$
\frac{d \ln K}{d(1 / T)}=\frac{-\Delta H}{R}
$$

Once the $\Delta \mathrm{G}$ and $\Delta \mathrm{H}$ values were determined, the entropy variation $(\Delta \mathrm{S})$ wasdetermined from equation 3:

$$
\Delta S=\frac{(\Delta H-\Delta G)}{T}
$$

In Table 2 was seen calculated thermodynamic parameters. The equilibrium was connected with temperature. Equilibrium constant decrease when temperature increase. Pigment:copigment complex was unstable at high temperature. The reaction was determined as reversibly because after cooling equilibrium constant increase again and it is important from a food technology point of view connected with pasteurization, commonly applied in fruit processing.

All values changes of $\Delta G$ (Table 2) were negative, suggesting spontaneous nature of the copigmentation reaction. The $\Delta \mathrm{G}$ dependence (Figure 3) reveals more favorable interaction at $20 / 30{ }^{\circ} \mathrm{C}$ than at $40 / 50{ }^{\circ} \mathrm{C}$, including after heating and subsequent cooling.The obtained 
values of enthalpy change $(\Delta \mathrm{H})($ Table 2$)$ define as an exothermic $(\Delta \mathrm{H}<0)$ one. The reaction was also accompanied by negative values of entropy $(\Delta \mathrm{S}<0)$, indicating an increase in the ordering of the system when the pigment/copigment complex is formed.

Table 2. Thermodynamic parameters of the copigmentation interaction in model solutions at different temperatures upon heating $(\mathrm{H})$ and subsequent cooling $(\mathrm{C})$

\begin{tabular}{|c|c|c|c|c|}
\hline Temperature & $\mathbf{K}^{\mathrm{a}}, \mathbf{M}^{-1}$ & $\Delta \mathrm{G}^{\mathrm{b}}, \mathrm{kJ} \mathrm{mol}^{-1}$ & $\Delta \mathbf{H}^{\mathrm{c}}, \mathbf{k J} \mathrm{mol}^{-1}$ & $\Delta \mathrm{S}^{\mathrm{d}}, \mathrm{JK}^{-1} \mathrm{~mol}^{-1}$ \\
\hline $20^{\circ} \mathrm{C}(\mathrm{H})$ & 2884.0 & -19.4 & -26.8 & -20.7 \\
\hline $30{ }^{\circ} \mathrm{C}(\mathrm{H})$ & 1737.8 & -18.9 & -26.5 & -23.1 \\
\hline $40^{\circ} \mathrm{C}(\mathrm{H})$ & 1412.5 & -18.8 & -25.4 & -24.1 \\
\hline $50^{\circ} \mathrm{C}(\mathrm{H})$ & 544.5 & -16.9 & -25.1 & -28.6 \\
\hline $40^{\circ} \mathrm{C}(\mathrm{C})$ & 1995.3 & -19.3 & -25.8 & -22.3 \\
\hline $30^{\circ} \mathrm{C}(\mathrm{C})$ & 2089.3 & -19.8 & -26.3 & -19.9 \\
\hline $20{ }^{\circ} \mathrm{C}(\mathrm{C})$ & 3467.4 & -19.9 & -26.7 & -19.9 \\
\hline
\end{tabular}

${ }^{a}$ Equilibrium constant.

${ }^{\mathrm{b}}$ Gibbs free energy.

${ }^{c}$ Enthalpy.

${ }^{\mathrm{d}}$ Entropy.

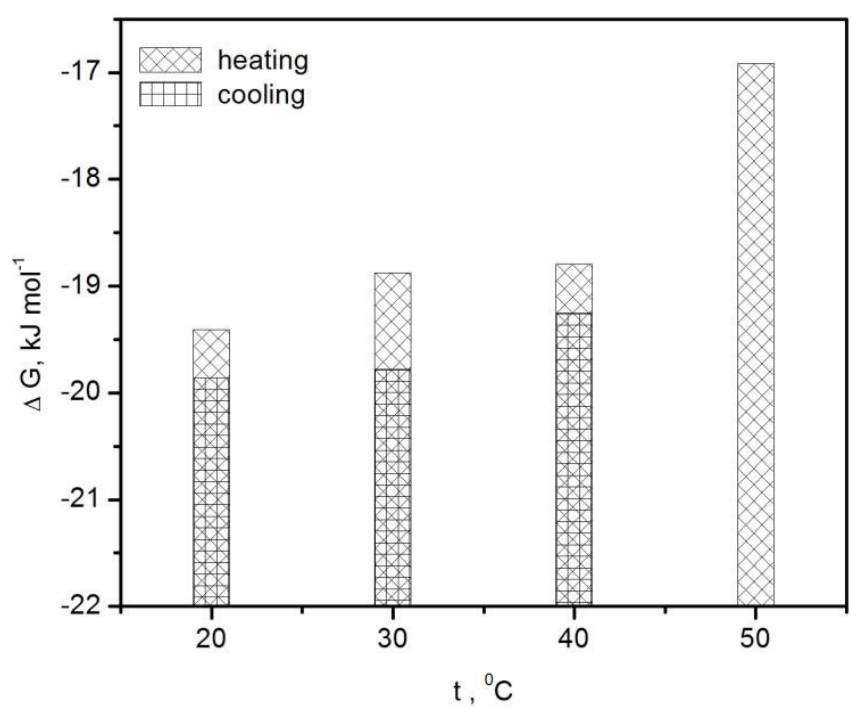

Fig. 3. Gibbs free energy relation versus temperatures in range between 20 to $50{ }^{\circ} \mathrm{C}$. 


\section{Conclusions}

The existence of copigmentation interaction between strawberry anthocyanins and rose petal polyphenols was observed. The values of Gibbs free energy $(\Delta G)$ and enthalpy $(\Delta H)$ changes define the copigmentation process as a spontaneous $(\Delta \mathrm{G}<0)$ and exothermic $(\Delta \mathrm{H}<0)$ one. The temperature dependences of $\Delta \mathrm{G}$ manifest the thermal reversibility of the copigmentation reaction. The latter might be important from a food technology point of view, allowing practice of polyphenols as natural anthocyanin-stabilizing agents.

The authors would like to thank the Research and Development Sector at the Technical University of Sofia for the financial support.

\section{References}

1. M. N. Clifford, J. of the Sci. of Food and Agric.80, 1063 (2000)

2. K. Hayashi, N. Ohara, A. Tsukui, Food Sci. and Tech. Int. 2, 30 (1996)

3. F. C. Stintzing, R. Carle, Trends in Food Sci. and Tech. 15, 19 (2004)

4. R. Brouillard, S. Chassaing, G. Isorez, M. Kueny-Stotz, P. Figueiredo, Recent advances in polyphenol research (New York, John Wiley \& Sons, 2010)

5. S. Asen, R. N. Stewart, K. H. Norris, Phytochem. 11, 1139 (1972)

6. A. Schieber, K. Mihalev, N. Berardini, P. Mollov, R. Carle, Zeitschriftfür Naturforschung 60, 379 (2005)

7. V. Shikov, D. Kammerer, K. Mihalev, P. Mollov, R. Carle, J. Agric. Food Chem. 56, 8521 (2008)

8. P. Mollov, K. Mihalev, V. Shikov, N. Yoncheva, V. Karagyozov, Innov. Food Sci. \& Emerg. Technol. 8, 318 (2007)

9. V. Shikov, K. Mihalev, N. Yoncheva, V. Karagyozov, P. Mollov, Jour. of Eco Agri Tour. 8, 231 (2012)

10. P. J. Elving, J. M. Markowitz, I. Rosenthal, Anal. Chem. 28, 1179 (1956)

11. J. M. Baranac, N. A. Petranović, J. M. Dimitrić-Marković, J. Agric. Food Chem. 44, 1333 (1996)

12. B. Malaj, C. De Simone, A. Quartarolo, N. Russo, Food Chem. 141, 3614 (2013)

13. R. Brouillard, Phytochemistry 22, 1311 (1983)

14. I. Petrova, V. Shikov, V. Gandova, K. Mihalev, D. Dimitrov, Bulg. Chem. Comm. 49, 115 (2017) 